\title{
Influence of Soil Erosion Thickness on Soybean Yield and Coupling Mode of Water and Fertilizers of Black Soil in Northeast China
}

\author{
Hui Liu ${ }^{1}$, Yongxia $\mathrm{Wei}^{1,2,3,4 *}$, Long Wang ${ }^{1}$ and Xian $\mathrm{Wu}^{1}$ \\ ${ }^{1}$ College of Water Conservancy and Architecture, Northeast Agricultural \\ University, Harbin 150030, China \\ ${ }^{2}$ Collaborative Innovation Center of Grain Production Capacity Improvement in \\ Heilongjiang Province, Harbin 150030, China \\ ${ }^{3}$ Key Laboratory of High Efficiency Utilization of Agricultural Water Resources of \\ the Ministry of Agriculture, Harbin 150030, China \\ ${ }^{4}$ Key Laboratory of Water-saving Agriculture of Ordinary University in \\ Heilongjiang Province, Harbin 150030, China \\ xiaolaida@163.com
}

\begin{abstract}
Soil erosion is one of the most widespread ecological problems with the most serious damage worldwide. In the present study, the influence of soil erosion thickness on soybean yield of black soil in Northeast China is studied. With the pot experiment as the method, this study investigates the influence by peeling the surface black soil layer at 0, 5, $10,20,25$, and $30 \mathrm{~cm}$ to simulate different soil erosion thicknesses, establishes a quantitative model of soybean yield to explore the response of soybean yield to soil erosion thickness. The 4-D-optimum orthogonal design (416-A) is adopted to conduct the coupling experiment of water and fertilizers under erosion thicknesses of 0 and $15 \mathrm{~cm}$ so that the coupling modes of water and fertilizers under the two soil erosion thicknesses are established. The results show that soil erosion thickness has a significant influence on soybean growth, that is, with the increase in the soil erosion thickness, soybean plant height, pods and grains per plant all reduce, and soybean yield decreases in a Z-shaped curve, while yield reduction rate increases in a S-shaped curve, respectively. Water, along with $N, P$, and $K$ fertilizers, affect soybean yield, but the intensity varies with soil erosion thickness. Under the soil erosion thickness of $0 \mathrm{~cm}$, the order is: $W>P>N>K$. While under the soil erosion thickness of $15 \mathrm{~cm}$, the order is: $N>W>P>K$. With the increase in soil erosion thickness and the decrease in soil fertility, the effect of irrigation reduces, whereas that of fertilization increases. The research results can provide the theoretical basis for soil erosion prevention and control in the black soil region.
\end{abstract}

Keywords: black soil region, soil erosion thickness, soybean yield, coupling mode of water and fertilizers

\section{Introduction}

Soil erosion is one of the most widespread ecological problems with the most serious damage worldwide. It accelerates the process of land desertification, causes soil degradation and soil productivity reduction; affects the agricultural development and food security; and seriously restricts the sustainable development of society, economy, and ecology in the world [1-2]. The black soil region of Northeast China is the most important grain production base. However, this area is also one of six soil erosion regions in China because over half of its arable land is sloping, making it the most vulnerable part in the rural ecological environment and the main origin of soil erosion [3]. Serious land and 
water loss, especially in sloping land, causes the erosion of the black soil by $0.5 \mathrm{~cm}$ to $1 \mathrm{~cm}$ on average. As a result, black soil thickness decreases from $60 \mathrm{~cm}$ to $70 \mathrm{~cm}$ in the initial period of reclamation to $20 \mathrm{~cm}$ to $30 \mathrm{~cm}$ at present. In some regions, the black soil is eroded with the loess exposed [4-5]. Soil organic matter and nutrient contents decrease and soil bulk density increases with the loss of the fertile black soil layer. As a result, the water and fertilizer holding capacity of the soil is reduced and farmland productivity declines, thereby threatening the regional grain security and sustainable development of agriculture.

Although scholars have investigated the effects of soil erosion on crop yield and quality, differences exist in the quantitative description of these effects. Some scholars hold that crop yield is reduced in a concave-shaped curve along with the change in the degree of soil erosion [6]; some believe that the curve should have a convex shape [7]. Still others believe that a linear relationship exists between crop yield and soil erosion thickness [8-9]. In addition, increasing soil erosion presents the inevitable problem of determining the reasonable coupling mode of water and fertilizers under different degrees of soil erosion, which is missing at present. This paper contributes to the experimental research by peeling the surface black soil layer at different depths to simulate different soil erosion thicknesses. With the soybean as the research object and the pot experiment as the method, this study investigates the influence of soil erosion thickness on soybean yield, establishes a quantitative model to explore the response of soybean yield to soil erosion thickness [10]. Soil erosion thicknesses of 0 and $15 \mathrm{~cm}$ are selected to conduct the coupling experiment of water and fertilizers on soybean because the two soils have significantly different degrees of fertility, such that the coupling modes of water and fertilizers under the two soil erosion thicknesses are established. The research results can provide a theoretical basis for the efficient use of water and soil resources in the black soil region.

\section{Materials and Methods}

\subsection{Introduction of the Experiment Zone}

The experiment was carried out in the test base of Hongxing Farm, Agriculture Bureau of Heilongjiang Agricultural Reclamation Department, Beian Branch located in the typical black soil belt in Northeast China in 2012 and 2013. Located in the transitional region from the west of Xiaoxinganling Mountains to Songnen Plain, the experimental zone is an upland region, with land sloping from east to west. The slope is gentle and long, with a gradient of $3^{\circ}$ to $5^{\circ}$. This area belongs to sub-humid continental monsoon climate that features hot and rainy weather in summer, with $2254.5^{\circ} \mathrm{C}$ of effective accumulated temperature greater than or equal to $10{ }^{\circ} \mathrm{C}, 2364.2$ hours of sunshine, and about 105 days of frost-free season. The average annual precipitation in this area is $553 \mathrm{~mm}$, in which the value is $401.7 \mathrm{~mm}$ during July and September, accounting for three fourths of the total precipitation throughout the year. The winter is cold and long. The plough layer is mainly the black soil at the depth of $30 \mathrm{~cm}$. The surface layer is loose, with heavy and sticky subsoil and poor permeability. The vegetation in the arable land is mainly corn and soybean. The agricultural products have low ability to withstand natural disasters and are greatly affected by the weather. In addition to the concentrated rainfall with short duration and high intensity, the soil in the sloping land is severely eroded, leading to the reduction in land productivity. 


\subsection{Experiment Design}

The pot experiment was conducted in a mobile rain-proof shed. Soil erosion thicknesses of $0,5,10,20,25$, and $30 \mathrm{~cm}$ were adopted to perform a single factor experiment to explore the influence of soil erosion thickness on crop yield in the black soil region. The tested crop is soybean 1778 and the tested soil is the local plough layer of black soil. The soil was obtained from $0,5,10,15,20,25$, and $30 \mathrm{~cm}$ below the surface layer to simulate the plough layer soil with soil erosion thickness of $0,5,10,15,20,25$, and $30 \mathrm{~cm}$, including 7 treatments and 3 repetitions, for a total of 21 pots. Up to 10 seeds were planted in each pot and 4 seedlings were retained. All treatments adopted the same water and fertilizer management mode. The amount of fertilizer applied to each pot was calculated according to the recommended standard for large fields. Phosphate fertilizer, potash fertilizer, and $40 \%$ of the total amount of nitrogen fertilizer were used as basal to be spread in the pots simultaneously. The remaining nitrogen fertilizer was used for top-dressing in three periods: flowering period, pod bearing period, and seed-filling period. Irrigation was controlled according to the standard of making the soil moisture content account for $80 \%$ of the field moisture capacity. The soil was weighed every day during the whole growth period and water was added to reach the watering standard.

The coupling experiment of water and fertilizers was conducted under the soil erosion thicknesses of 0 and $15 \mathrm{~cm}$ to explore reasonable irrigation and fertilization technologies. The 4-D-optimum orthogonal design (416-A) was adopted by setting nitrogenous fertilizer $(\mathrm{N})$, phosphate fertilizer $(\mathrm{P})$, potash fertilizer $(\mathrm{K})$, and irrigation amount $(\mathrm{W})$ as the four factors for 16 treatments and three repetitions. The level codes of each factor are shown in Table 1.

Table 1. Level Codes of Experiment Factors

\begin{tabular}{cccccccc}
\hline \multicolumn{3}{c}{ Coded value } & \multicolumn{5}{c}{ Actual value } \\
$x_{1}$ & $x_{2}$ & $x_{3}$ & $x_{4}$ & $\mathrm{~W}(\%)$ & $\mathrm{N}\left(\mathrm{kg} / \mathrm{hm}^{2}\right)$ & $\mathrm{P}\left(\mathrm{kg} / \mathrm{hm}^{2}\right)$ & $\mathrm{K}\left(\mathrm{kg} / \mathrm{hm}^{2}\right)$ \\
\hline 1.685 & 1.685 & 1.685 & 1.784 & 90 & 280 & 150 & 180 \\
1 & 1 & 1 & 0.644 & 81.87 & 235.28 & 125.61 & 127.83 \\
0 & 0 & 0 & -0.908 & 70 & 170 & 90 & 56.81 \\
-1 & -1 & -1 & -1.494 & 58.13 & 104.72 & 54.39 & 30 \\
-1.685 & -1.685 & -1.685 & & 50 & 60 & 30 & \\
\hline
\end{tabular}

Note: the irrigation amount accounts for the percentage of field moisture capacity

\subsection{Observation Indexes and Methods}

The potassium dichromate-sulfuric acid process is adopted for soil organic matter. The micro-Kjeldahl method is employed for total N. The lapis causticus-Mo-Sb colorimetry and lapis causticus-flame photometry methods are used for total P. The alkali $\mathrm{N}$-proliferation method is adopted for alkali-hydrolyzable $\mathrm{N}$. The NaHCO 3 extraction-Mo-Sb colorimetry and ammonium acetate extraction-flame photometry methods are adopted for available P. The cutting ring method is used for soil bulk density. The Wilkes method is employed for field moisture capacity [11].

All soybeans are weighed during the harvest period and measured in terms of plant height, number of pods, grains per plant, and 100-seed weight.

All indexes adopt the mean values and are processed and statistically analyzed with Excel, SAS V9, and Mathematica 5.0. 


\section{Results}

\subsection{Influence of Soil Erosion Thickness on Soybean Yield}

Crop yield is one of the main indicators of soil productivity [12-14]. A less eroded black soil layer has little influence on soybean yield (Figure 1). Soybean yield decreases from $52.37 \mathrm{~g} /$ pot to $50.52 \mathrm{~g} / \mathrm{pot}$, a reduction of $3.53 \%$, when the soil erosion thickness is $5 \mathrm{~cm}$. The soybean yield shows the most rapid decline $(29.48 \mathrm{~g} / \mathrm{pot}$, a reduction of $43.71 \%$ ) when soil erosion thickness is about $20 \mathrm{~cm}$; thereafter, the soybean yield declines slowly. When the soil erosion thickness is 25 and $30 \mathrm{~cm}$, the soybean yield is $24.26 \mathrm{~g} /$ pot and $22.57 \mathrm{~g} / \mathrm{pot}$, a reduction of $53.68 \%$ and $56.90 \%$, respectively. Given that the same water and fertilizers are adopted for all treatments, the difference between soybean yields must be caused by soil erosion thickness. The change in soybean yield with soil erosion thickness can be illustrated by the Z-shaped curve equation:

$$
y=\frac{1}{0.0155+0.00312 e^{0.08 x}}
$$

The change in soybean yield reduction rate with soil erosion thickness shows an S-shaped curve and can be expressed by equation:

$$
y_{1}=\frac{1}{0.0170+1.0284 e^{-0.2552 x}}
$$

where $x$ refers to the soil erosion thickness $(\mathrm{cm}), y$ refers to soybean yield $(\mathrm{g} / \mathrm{pot})$, and $y_{1}$ refers to soybean yield reduction rate $(\%)$.

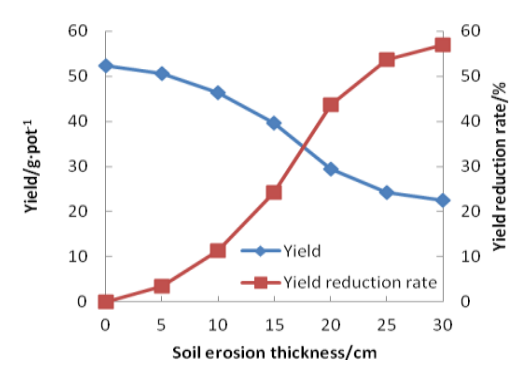

Figure 1. Soybean Yield and Yield Reduction Rate under Different Soil Erosion Thicknesses

The same soil erosion thickness causes different yield reduction amplitudes. With the increase in erosion thickness, the yield reduction caused by every $5 \mathrm{~cm}$ of soil erosion shows a similar change trend with the yield reduction rate; that is, initially increasing rapidly, and then slightly, finally tending to be stable (Figure 2).

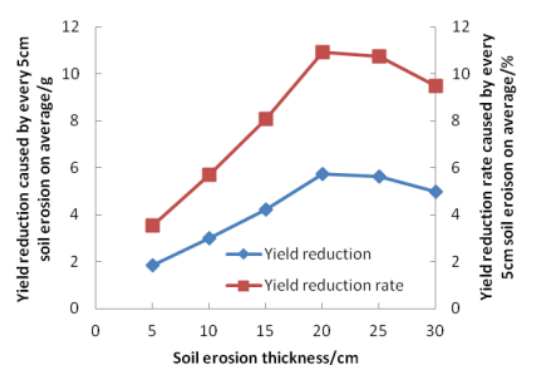

Figure 2. Average Yield Reduction Caused by Every $5 \mathrm{~cm}$ of Soil Erosion 


\subsection{Influence of Soil Erosion Thickness on Soybean Plant Height and Indicators of Soybean Yield}

Plant height, number of pods and grains per plant, and 100-seed weight are important indicators of soybean growth [15-19]. Under different soil erosion thicknesses, the influence of four indexes on soybean yield from great to little is as follows: number of grains per plant, number of pods per plant, plant height, and 100-seed weight, in which the first three have significant influence on soybean yield with determination coefficients of $0.98281,0.94028$, and 0.91610 , respectively, whereas the last one, with a determination coefficient of 0.16336 , has an insignificant influence.

As shown in Figure 3, soybean plant height, number of pods per plant, and number of grains per plant decrease and show linear relationship with the increase in soil erosion thickness. The regression equation between the number of grains per plant and soil erosion thickness has the largest slope, indicating that soil erosion thickness has the greatest influence on the number of grains per plant, followed by the number of pods per plant and plant height. The order is consistent with the influence order of the three indexes on soybean yield.

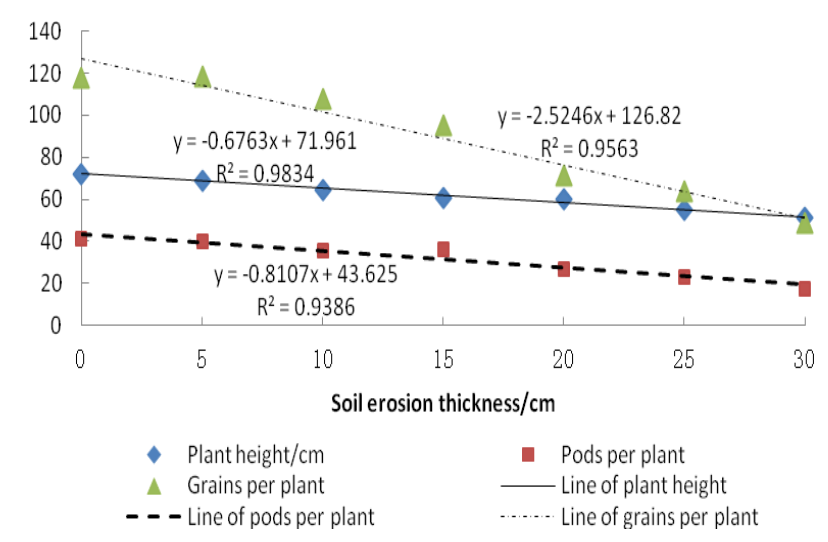

Figure 3. Change in the Yield Components of Soybean with Soil Erosion Thickness

\subsection{Coupling Modes of Water and Fertilizers at Different Soil Erosion Thicknesses}

Soil erosion thicknesses of 0 and $15 \mathrm{~cm}$ are selected to conduct the coupling experiment of water and fertilizers on soybean. The regression models of soybean yield on $\mathrm{W}, \mathrm{N}, \mathrm{P}$, and $\mathrm{K}$ are established as follows:

$$
\begin{aligned}
y^{(1)}=55.00 & +7.75 x_{1}+1.07 x_{2}+0.29 x_{3}-2.07 x_{4}+1.53 x_{1} x_{2}+0.44 x_{1} x_{3}+0.75 x_{1} x_{4} \\
& +1.30 x_{2} x_{3}+0.08 x_{2} x_{4}+0.39 x_{3} x_{4}-2.59 x_{1}^{2}+5.32 x_{2}^{2}-3.13 x_{3}^{2}-0.28 x_{4}^{2} \\
y^{(2)}=32.39 & +5.61 x_{1}+1.34 x_{2}+0.28 x_{3}-1.77 x_{4}+1.83 x_{1} x_{2}+0.57 x_{1} x_{3}+0.80 x_{1} x_{4} \\
& +1.61 x_{2} x_{3}-1.18 x_{2} x_{4}+0.43 x_{3} x_{4}-3.82 x_{1}^{2}+10.89 x_{2}^{2}-2.46 x_{3}^{2}-0.04 x_{4}^{2}
\end{aligned}
$$

where $y^{(1)}$ and $y^{(2)}$ refer to soybean yield under the soil erosion thickness of 0 and 15 $\mathrm{cm}$, respectively; $x_{1}, x_{2}, x_{3}$, and $x_{4}$ refer to the coded value of $\mathrm{W}, \mathrm{N}, \mathrm{P}, \mathrm{K}$, respectively.

The variance analysis results of both equations are significant, which show a good fit of soybean yield relative to the four factors. The results of the regression coefficient test show that all four factors and their interactions influence soybean yield and the two 
equations have the same significant items, which are the linear terms of $\mathrm{W}, \mathrm{N}$, and $\mathrm{K}$; the interactive terms of $\mathrm{W}$ and $\mathrm{N}, \mathrm{W}$ and $\mathrm{K}, \mathrm{N}$ and $\mathrm{P}$; the quadratic terms of $\mathrm{W}, \mathrm{N}$, and $\mathrm{P}$.

\subsection{Analysis of Main Factor Effects}

The analysis of main factor effects aims to identify the degree of influence of each factor on soybean yield [20]. Since the regression equations are multivariate non-linear models, the contribution rates of the four factors on soybean yield are calculated using the contribution rate. The results are shown in Table 2.

Table 2. Contribution Rates of Factors

\begin{tabular}{cccccc}
\hline & & \multicolumn{3}{c}{$y^{(1)}$} & \multicolumn{2}{c}{$y^{(2)}$} \\
\cline { 3 - 6 } & & Contribution rate & $\begin{array}{c}\text { Percentage } \\
\text { contribution rate }(\%)\end{array}$ & Contribution rate & $\begin{array}{c}\text { Percentage } \\
\text { contribution rate (\%) }\end{array}$ \\
\hline$\Delta_{1}$ & $(\mathrm{~W})$ & 3.443 & 29.536 & 3.460 & 27.263 \\
$\Delta_{2}$ & $(\mathrm{~N})$ & 2.984 & 25.598 & 3.484 & 27.453 \\
$\Delta_{3}$ & $(\mathrm{P})$ & 3.297 & 28.283 & 3.310 & 26.081 \\
$\Delta_{4}$ & $(\mathrm{~K})$ & 1.933 & 16.582 & 2.437 & 19.203 \\
\hline
\end{tabular}

Table 2 shows that under the two soil erosion thicknesses, the influence degree of the four factors on soybean yield are in the following orders:

$$
0 \mathrm{~cm}: \mathrm{W}>\mathrm{P}>\mathrm{N}>\mathrm{K} \quad 15 \mathrm{~cm}: \mathrm{N}>\mathrm{W}>\mathrm{P}>\mathrm{K}
$$

\subsection{Analysis of Single Factor Effects}

Considering the effects of quadratic term in the regression equations (3) and (4) and using the dimensionality reduction method, this study determines the regression sub-models of W, N, P, and K on soybean yield by fixing three of the four factors at zero level to resolve the single-factor effects [21-24].

Figure 4 shows the influence of each factor on soybean yield. When the N, P, and K are fixed at zero level, soybean yield first increases and then decreases under different soil erosion thicknesses with the increase in $\mathrm{W}$. By contrast, soybean yield exhibits a more negligible change with the change in $\mathrm{W}$ under the soil erosion thickness of $15 \mathrm{~cm}$ than 0 $\mathrm{cm}$, which indicates a reducing effect of $\mathrm{W}$ with low soil fertility (Figure 4(a)). Figure 4(b) shows that when the other factors are fixed at zero level, soybean yield first decreases and then increases with the increase in $\mathrm{N}$, reaching the minimum value within the vicinity of zero level. Meanwhile, soybean yield exhibits a larger change with the change in $\mathrm{N}$ under the soil erosion thickness of $15 \mathrm{~cm}$ than $0 \mathrm{~cm}$, which indicates an increasing effect of $\mathrm{N}$ with low soil fertility. Figure 4(c) shows that when the other factors are fixed at zero level, the increase in $\mathrm{P}$ causes soybean yield to first increase and then decrease, reaching the maximum value within the vicinity of zero level. Meanwhile, the ripples of the two curves are similar, which indicates a slight change in the effect of $P$. Figure 4(d) shows that when the other factors are fixed at zero level, soybean yield decreases slightly with the increase in $\mathrm{K}$ under different soil erosion thicknesses, and fluctuation is relatively flat, indicating a small influence of $\mathrm{K}$ on soybean yield. 

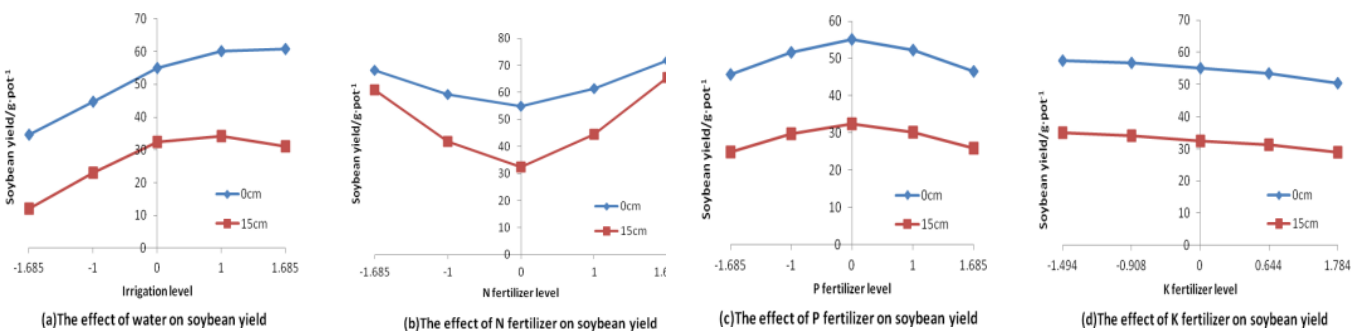

Figure 4. Analysis of Single Factor Effects

\subsection{Analysis of Interaction Effects between Factors}

The influences of the four factors on soybean yield are not isolated, but rather interact with one another. In regression equations (3) and (4), the regression sub-models are obtained by fixing two factors at zero level [21-24]. On the basis of the results of the regression coefficient test, the significant interaction terms of $\mathrm{W}$ and $\mathrm{N}, \mathrm{W}$ and $\mathrm{K}$, as well as $\mathrm{N}$ and $\mathrm{P}$ are selected to analyze the interaction effects. The coupling effect diagrams under different soil erosion thicknesses are shown in Figure 5 and Figure 6.

Figure 5(a) shows that under the soil erosion thickness of $0 \mathrm{~cm}$, soybean yield increases with the increase in $\mathrm{W}$ when $\mathrm{N}$ remains constant, whereas the yield first increases and then decreases with the increase in $\mathrm{N}$ when $\mathrm{W}$ remains constant. The maximum yield appears in the level combination of high $\mathrm{W}$ and high N. Figure 6(a) shows that under the soil erosion thickness of $15 \mathrm{~cm}$, soybean yield has a more sensitive response to $\mathrm{W}$ and $\mathrm{N}$. When $\mathrm{N}$ remains at a significantly higher level interval of $(0,1.685)$ and takes a fixed level, soybean yield increases with the increase in W. By contrast, when $\mathrm{N}$ remains in a significantly lower level interval of $(-1.685,0)$ and takes a fixed level, soybean yield first increases and then decreases with the increase of W. Meanwhile, soybean yield first decreases and then increases with the increase in $\mathrm{N}$ when $\mathrm{W}$ remains constant, and the maximum yield appears in the level combination of high $\mathrm{W}$ and high $\mathrm{N}$. Adequate water can improve the utilization of $\mathrm{N}$, and under adequate water conditions, decreased $\mathrm{N}$ can produce high soybean yield. However, the highest $\mathrm{N}$ should be selected to obtain a significantly higher yield, and under the level combination of high $\mathrm{W}$ and high $\mathrm{N}$, soybean yield would sustain an increase with the increase in $\mathrm{N}$.
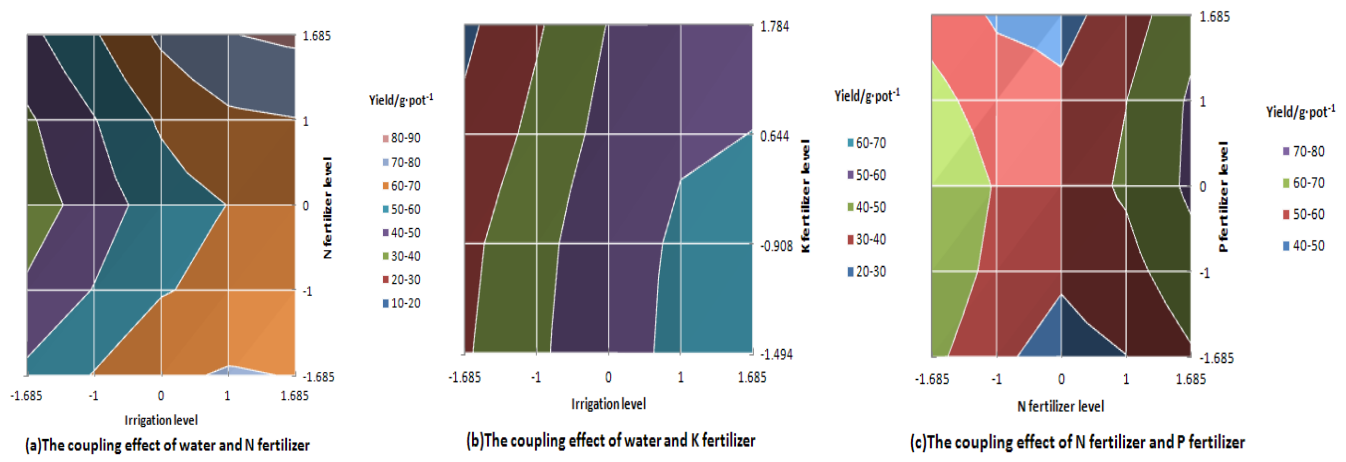

Figure 5. Coupling Effect Diagrams at a Soil Erosion Thickness of $0 \mathrm{~cm}$ 

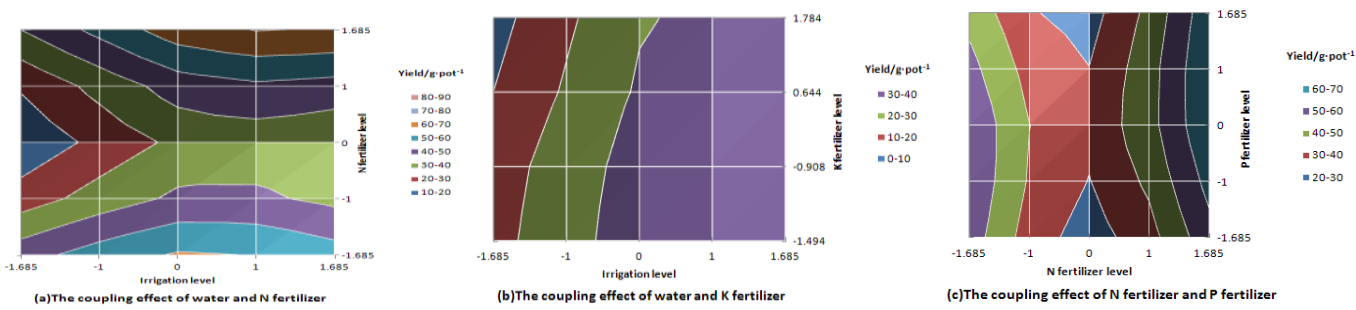

Figure 6. Coupling Effect Diagrams at a Soil Erosion Thickness of $15 \mathrm{~cm}$

Figure 5(b) shows that under the soil erosion thickness of $0 \mathrm{~cm}$, soybean yield increases with the increase in $\mathrm{W}$ when $\mathrm{K}$ remains constant, but slightly decreases with the increase in $\mathrm{K}$ when $\mathrm{W}$ remains constant. The maximum of yield appears in the level combination of high $\mathrm{W}$ and low K. Figure 6(b) shows that under the soil erosion thickness of $15 \mathrm{~cm}$, the change in soybean yield with $\mathrm{W}$ and $\mathrm{K}$ is the same as that of $0 \mathrm{~cm}$, and the maximum yield appears in the level combination of high $\mathrm{W}$ and low $\mathrm{K}$. The difference is that under the soil erosion thickness of $15 \mathrm{~cm}$, when $\mathrm{W}$ remains in a significantly higher level interval of $(0,1.685)$, soybean yield increases slightly regardless of $\mathrm{K}$, indicating a decreasing effect of $\mathrm{W}$ with the decrease in $\mathrm{K}$ in soil fertility.

Figure 5(c) shows that under the soil erosion thickness of $0 \mathrm{~cm}$, the fluctuation of soybean yield is much smoother than that of $15 \mathrm{~cm}$. Soybean yield first increases and then decreases with the increase in $\mathrm{P}$ when $\mathrm{N}$ remains constant, but first decreases and then increases with the increase in $\mathrm{N}$ when $\mathrm{P}$ remains constant. The maximum yield appears in the level combination of high $\mathrm{N}$ and proper P. Figure 6(c) shows that under the soil erosion thickness of $15 \mathrm{~cm}$, the change in soybean yield with $\mathrm{N}$ and $\mathrm{P}$ is the same as that of $0 \mathrm{~cm}$, but the yield has a more sensitive response to $\mathrm{N}$ and a less sensitive response to $\mathrm{P}$. Such observation indicates a highly significant effect of $\mathrm{N}$ and a less significant effect of $\mathrm{P}$ with the decrease in soil fertility.

According to the above analysis, the ideal coupling modes of water and fertilizers should be high $\mathrm{N}$, proper $\mathrm{P}$, and low $\mathrm{K}$ under the condition of sufficient $\mathrm{W}$, which could help increase soybean yield.

\subsection{Optimum Coupling Mode of Water and Fertilizers}

The frequency analysis is used to identify the optimum coupling mode of water and fertilizers [20]. According to the experiment design, 500 schemes are found for the four factors. Among these schemes, 48 represent a case in which soybean yield is over $70 \mathrm{~g} /$ pot under the soil erosion thickness of $0 \mathrm{~cm}$, while 53 represent a case in which soybean yield is over $60 \mathrm{~g} / \mathrm{pot}$ under the soil erosion thickness of $15 \mathrm{~cm}$. These schemes are statistically analyzed to determine the optimum coupling mode of water and fertilizers, and the results are shown in Table 3.

Table 3. Results of Frequency Statistics at Different Soil Erosion Thicknesses

\begin{tabular}{cccccc}
\hline & & $x_{1}(\mathrm{~W})$ & $x_{2}(\mathrm{~N})$ & $x_{3}(\mathrm{P})$ & $x_{4}(\mathrm{~K})$ \\
\hline \multirow{4}{*}{$0 \mathrm{~cm}$} & 1.098 & 1.028 & 0.239 & -0.387 \\
& Mean & 0.618 & 1.323 & 0.899 & 1.197 \\
& Standard deviation & $(0.919$, & $(0.641$ & $(-0.022,0.500)$ & $(-0.735,-0.040)$ \\
\hline \multirow{3}{*}{$15 \mathrm{~cm}$ confidence } & $1.277)$ & $1.409)$ & 0.267 & -0.207 \\
& interval & 0.835 & 1.049 & 1.039 & 1.225 \\
& Mean & 0.688 & 1.331 & $(-0.019,0.554)$ & $(-0.544,0.131)$ \\
\hline
\end{tabular}


The optimum water and fertilizers levels in Table 6 are converted into actual values to determine the optimum coupling mode of water and fertilizers. Under the soil erosion thickness of $0 \mathrm{~cm}$, the $\mathrm{W}$ accounts for $80.91 \%$ to $85.16 \%$ of field moisture capacity, the $\mathrm{N}$ is $211.84 \mathrm{~kg} / \mathrm{hm}^{2}$ to $261.98 \mathrm{~kg} / \mathrm{hm}^{2}$, the $\mathrm{P}$ is $89.22 \mathrm{~kg} / \mathrm{hm}^{2}$ to $107.81 \mathrm{~kg} / \mathrm{hm}^{2}$, and the $\mathrm{K}$ is $71.37 \mathrm{~kg} / \mathrm{hm}^{2}$ to $103.14 \mathrm{~kg} / \mathrm{hm}^{2}$. The soybean yield may be over $70 \mathrm{~g} /$ pot with a probability of $95 \%$. By contrast, under the soil erosion thickness of $15 \mathrm{~cm}$, the W accounts for $77.67 \%$ to $82.17 \%$ of field moisture capacity, the $\mathrm{N}$ is $214.52 \mathrm{~kg} / \mathrm{hm}^{2}$ to $262.44 \mathrm{~kg} / \mathrm{hm}^{2}$, the $\mathrm{P}$ is $89.32 \mathrm{~kg} / \mathrm{hm}^{2}$ to $109.73 \mathrm{~kg} / \mathrm{hm}^{2}$, and the $\mathrm{K}$ is $80.11 \mathrm{~kg} / \mathrm{hm}^{2}$ to $110.99 \mathrm{~kg} / \mathrm{hm}^{2}$. The soybean yield may be over $60 \mathrm{~g} /$ pot with a probability of $95 \%$. A comparison of the optimum coupling mode under the tow soil erosion thicknesses reveals that the $\mathrm{W}$ becomes smaller, whereas the $\mathrm{N}, \mathrm{P}$, and $\mathrm{K}$ become greater, but the maximum yield is reduced by an average of $10 \mathrm{~g} /$ pot.

\section{Discussion}

Soil erosion is one of the most widespread ecological problems in the world [4]. In the black soil region of Northeast China, where is the most important grain production base and one of six soil erosion regions in China, serious land and water loss causes a decrease in the black soil thickness, leading to a steep decline in crop yield. The present study investigates the influence of soil erosion thickness on soybean yield and establishes the coupling modes of water and fertilizers under different soil erosion thicknesses by comparing the response of soybean yield to water supply and fertilizers input in the black soil region of China.

Increase in soil erosion thickness reduces soil nutrients and decreases fertilizer and water supply abilities, thereby affecting soybean growth and resulting in a diminished yield. However, differences exist in the quantitative description of the influence. Some scholars hold that crop yield is reduced in a concave-shaped curve along with the increase in soil erosion thickness [6]; some believe that the curve should be in the convex-shaped [7], and others think a linear relationship exists between crop yield and soil erosion thickness [8-9]. In the present study, soybean yield decreases in a Z-shaped curve with the increase in soil erosion thickness $(p<0.01)$, which is more complex than the three curves above (Figure 1). The influence of soil erosion thickness on soybean growth is mainly reflected by the reduction in plant height, decrease in the number of pods and grains per plant, and thus the decline of soybean yield (Figure 3 ).

Soil erosion thickness can affect crop yield reduction rate as well. Bakker et al., (2004) [11] reported that the yield reduction rate caused by every $10 \mathrm{~cm}$ of erosion of soil was $26.6 \%$, which is greater than the result in the present study (Figure 2). Zhang et al. (2006) [10] found that when soil erosion thickness was $5,10,20$, and $30 \mathrm{~cm}$, the yield reduction rate was $3.1 \%, 3.2 \%, 33.2 \%$, and $59.2 \%$, respectively. In this study the yield reduction rate with soil erosion thickness can be significantly $(\mathrm{p}<0.01)$ expressed by an $\mathrm{S}$-shaped curve (Figure 1). The yield reduction rate is close to a content of $58.82 \%$ with the increase in soil erosion thickness, which is attributed to the most serious erosion.

Soil erosion thicknesses of 0 and $15 \mathrm{~cm}$ are selected to conduct the coupling experiment of water and fertilizers on soybean. The regression models of soybean yield on W, N, P, and K are both non-linear. All the four factors and their interactions influence soybean yield. The regression equations can objectively reflect the influence of irrigation and fertilization amounts on soybean yield under different soil erosion thicknesses and can serve as the basis for prediction.

$\mathrm{W}, \mathrm{N}, \mathrm{P}$, and $\mathrm{K}$ all influence soybean yield, but the intensity varies with the soil erosion thickness. With the increase in soil erosion thickness, the effect of irrigation is reduced, whereas that of fertilization increases. The ideal coupling mode of water and fertilizers should be high $\mathrm{N}$, proper $\mathrm{P}$, and low $\mathrm{K}$ under the condition of sufficient $\mathrm{W}$, which could help increase soybean yield. Furthermore, to obtain maximum soybean yield 
in the experiment zone, the optimal amount of water and fertilizers under different soil erosion thicknesses should be given in accordance with principles above.

\section{Acknowledgements}

The authors would like to acknowledge the financial support from the National Natural Science Foundation of China (51479033); the National Key Technology R\&D Project (2007BAD88b01, 2014BAD12B01, 2014BAD12B01-1-3); Science Foundation for Doctorate Research of Northeast Agricultural University; and Plan Program of Technology Innovation Team of Northeast Agricultural University (CXT003-2-3).

\section{References}

[1] L. Zhu, W. Feng and W. Zhu, "Progress of '3S' Technique Application in Soil Erosion Study", Progress in Geography, vol. 27, no. 6, (2008), pp. 57-62.

[2] Z. Li, B. Zhu and P. Li, "Advancement in Study on Soil Erosion and Soil and Water Conservation", Acta Pedologica Sinica, vol. 45, no. 5, (2008), pp. 802-809.

[3] J. He, Q. Cai and X. Wang, "Study on Optimized Patterns of Soil and Water Conservation Measures on Sloping Fields in Rocky Mountainous Area of Northern China", Geographical Research, vol. 29,no. 6, (2010), pp. 1017-1026.

[4] Y. Wei, Z. Zhang and Y. Zhao, "Theoretical and Technical Study on Soil and Water Conservation in Sloping Farmland", China Agriculture Press, (2010).

[5] H. Zhao, "Status Quo, Causes and Prevention of Soil Erosion in the Black Soil Region of Northeast China", Water Conservancy Science and Technology and Economy, vol. 14, no. 6, (2008), pp. 477-478,

[6] S. E. Obalum, M. M. Buri, J.C. Nwite, H, Y. Watanabe, C. A. Igwe and T. Wakatsuki, "Soil Degradation-Induced Decline in Productivity of Sub-Saharan African Soils: The Prospects of Looking Downwards the Lowlands with the Sawah Ecotechnology", Applied and Environmental Soil Science, vol 673926, (2012).

[7] Z. Wang, B. Liu, X. Wang, Xiaofei Gao and Gang Liu. Erosion Effect on the Productivity of Black Soil in Northeast China", Sci China Ser D-Earth Sci., vol. 5, no. 7, (2009), pp. 1005-1021.

[8] J.K. Mutegi, D.N. Mugendi, L.V. Verchot and J.B. Kung'u, "Combining Napier Grass with Leguminous Shrubs in Contour Hedgerows Controls Soil Erosion without Competing with Crops", Agrofor Syst., vol. 74, (2008), pp. 37-49.

[9] J. Liu, S. Tu, Y. Guo and Q. Jia, "Effect of Soil Erosion on Productivity of Sloping Field in a Micro-plot Experiment", Agricultural Science \& Technology, vol. 14, no. 1, (2013), pp. 127-130.

[10] X. Zhang, X. Liu, Y. Sui, S. Zhang, J. Zhang, H. Liu and S. J. Herbert, "Effects of Artificial Topsoil Removal on Soybean Dry Mater Accumulation and Yield”, Soybean Science, vol. 2, no. 2, (2006), pp. 123-126.

[11] M. M Bakker, G. Govers and M D A Rounsevell, "The Crop Productivity-Erosion Relationship: an Analysis Based on Experimental Work", Catena, vol. 57, no.1, (2004), pp. 55-76.

[12] R. Jia, X. Zhao and C. Du, "Evaluation on Productivity Decreased by Soil and Water Loss in the Southern Loess Plateau", Journal of Northwest Forestry University, vol. 19, no. 3, (2004), pp. 77-81.

[13] B.Mehdizade, H.Asadi, M.Shabanpour and H. Ghadiri, "Impact of Erosion and Tillage on the Productivity and Quality of Selected Semiarid Soils of Iran”, International Agrophysics, vol. 27, (2013), pp. 291-297.

[14] C. Biggelaar, R. Lal, K. Wiebe, H. Eswaran, V. Breneman and P. Reich, "The Global Impact of Soil Erosion on Productivity II: Effects on Crop Yields and Production Over Time", Advances in Agronomy, vol. 81, (2004), pp. 49-95.

[15] B. Zhu, F. Kuang, M. Gao, T. Wang, X. Wang and J. Tang, "Effects of Soil Thickness on Productivity of Sloping Cropland of Purple Soil", Journal of Mountain Science, vol. 27, no. 6, (2009), pp. 735-739.

[16] Z. Sun, X. Duan, Y. Xie and G. Liu, "The Effect of Erosion on Soybean Yield and Nutrient Supplying Capacity of Black Soil”, Chinese Journal of Soil Science, vol. 43, no. 6, (2012), pp. 1473-1479.

[17] Q. Chen, K. Wang, S. Qi, J. Li and X. Wu, "Soil Erosion and Its Relations to Slope Field Productivity in Hilly Gully Area of Loess Plateau and Dry-hot Valley of Jinshajiang River", Bulletin of Soil and Water Conservation, vol. 25,no. 3, (2005), pp. 29-32.

[18] M. Fan, R. Lal, J. Cao, L. Qiao, Y. Su, R. Jiang and F. Zhang, "Plant-Based Assessment of Inherent Soil Productivity and Contributions to China's Cereal Crop Yield Increase since1980", PLOS ONE, vol. 8, no. 9, (2013). 
[19] Z. Li, J. Huang, G. Zeng, X. Nie, W. Ma, W. Yu, W. Guo and J. Zhang, "Effect of Erosion on Productivity in Subtropical Red Soil Hilly Region: A Multi-Scale Spatio-Temporal Study by Simulated Rainfall”, PLOS ONE, vol. 8, no. 10, (2013).

[20] S. Feng, "Study on Water and Fertilizer Coupling Pattern of Drip Irrigation Soybean in the Western Semi-Arid area of HeilongjiangProvince", Northeast Agricultural University, (2011).

[21] K. Ronnenberg and K. Wesche, "Effects of Fertilization and Irrigation on Productivity", Plant Nutrient Contents and Soil Nutrients in Southern Mongolia, Plant Soil, vol. 340, (2011), pp. 239-251.

[22] W. Li, J. Xu and Z. Li, "Irrigation and Fertilizer Application of Dry-Period Affect Yield of Spring Wheat and Water Use Efficiency in Semi-Arid Regions", Journal of Lanzhou University (Natural Sciences), vol. 48, no. 3, (2012), pp. 76-82.

[23] X. Zhou, Y. Teng, M. Wang and Z. Zhang, "Study on Couple Effect of Water and Fertilizer of Soybean in Northeast Semiarid Area", Journal of Northeast Agricultural University, vol. 38, no. 4, (2007), pp. 405-411.

[24] W. Zheng, Y. Liu, Z. Zhang and L. Zhen, "Potential Maize Water-Fertilizer Productivity of Dryland Farming in the West Region of Heilongjiang Province”, Journal of Irrigation and Drainage, vol. 29, no. 4, (2010), pp. 136-139.

\section{Author}

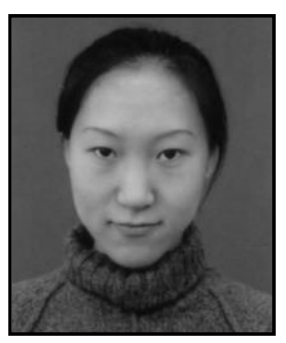

Hui Liu (1981-), female, born in Harbin, Heilongjiang Province, China. She is a Ph.D. student in the college of water conservancy and architecture at northeast agricultural university. Her research direction is agricultural water and soil engineering. 
International Journal of $\mathrm{u}-$ and $\mathrm{e}-$ Service, Science and Technology Vol.8, No.3 (2015) 